2. Continuing to strengthen IUPAC's infrastructure. We will be paying special attention to enabling the Secretariat to continue its creative and high-performing role as the engine that makes it possible for IUPAC's volunteer scientists to succeed. We will be building a more effective and more useful web presence for the Union, combining the strengths of the Secretariat with a task group of experts in web design and content who understand the needs of IUPAC. To make these and other things possible, we will continue to raise awareness within and outside the chemistry community about the myriad accomplishments IUPAC has made through its volunteers and their contributions to our projects.

3. Building collaborations with the sciences and the public. People are excited about chemistry-perhaps much more than we chemists realize. The recent flurry of articles in the popular press about the verification of discovery of element 115, and the enthusiastic recent celebrations for flerovium and livermorium, clearly shows that the public is interested in the posi- tive contributions of chemistry and is eager to learn more. IUPAC will also continue to work collaboratively with its sister scientific unions. We will continue to collaborate with decision makers to provide them with the objectively evaluated chemical science that they need to formulate sensible policy. And we will reaffirm and strengthen our ties to industrial companies and organizations, National Adhering Organizations, and worldwide chemical societies to further the work of the Union.

We in IUPAC are looking forward to a biennium filled with opportunities and challenges as we move into 2014 and onward toward our centennial in 2019. I look forward to working with everyone within and outside IUPAC to accomplish our goals.

Mark Cesa <mcesa@iupac.org> is president of IUPAC since January 2014. Previously in IUPAC he served as vice president in 2012-2013, and on the Committee on Chemistry and Industry as secretary (2000-2003), vice chair (2004-2005), and chair (2006-2009). Cesa is a process chemistry consultant with INEOS Nitriles in Naperville, Illinois, USA.

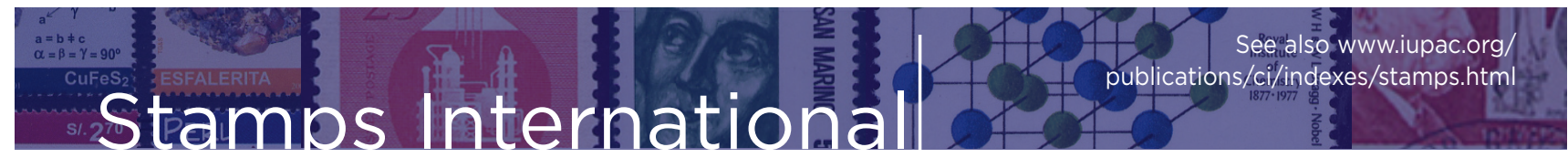

\section{Crystal Structure Número Uno}

Welcome to the International Year of Crystallography (IYCr), an exciting yearlong celebration of crystallography and its contributions to fields as diverse as chemistry, nanotechnology, mineralogy, physics, molecular biology, medicine, and materials science. The year 2014 marks the centennial of the Nobel Prize in Physics that the German physicist Max von Laue (1879-1960) received for his discovery of the diffraction of X-rays by crystals in 1912. Furthermore, von Laue's seminal work confirmed that X-rays were a form of electromagnetic radiation (a controversial topic since their discovery by Röntgen in 1895) and

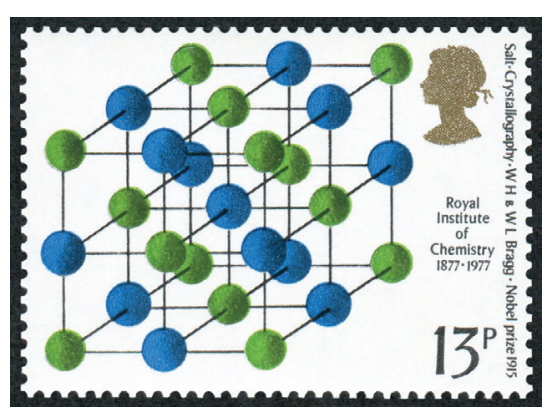

chloride, bromide and iodide were described for the first time in a paper published in September of 1913 in the Proceedings of the Royal Society of London, effectively giving birth to the science of X-ray crystallography. A staggering number of crystal structures have been determined in the ensuing decades and the Cambridge Structural Database, the main repository for crystallographic data of organic and organometallic compounds, contains nowadays more than 700000 entries! The stamp illustrated in this note shows the archetypical face-centered cubic structure of sodium chloride and honors the Braggs, who received the 1915 Nobel Prize in Physics "for their services in the analysis of crystal structure by means of that crystalline materials consisted of organized, threedimensional arrays of atoms, molecules or ions. Before long, William Henry Bragg (1862-1942), a Professor of Physics at Leeds University, working collaboratively with his son William Lawrence (1890-1971) at Trinity College, Cambridge, realized that $X$-rays could be used to uncover the structure of crystals with atomic resolution. The structures of sodium chloride and potassium
X-rays." Interestingly, the Braggs remain to this date the only father and son team to have jointly received a Nobel Prize and, perhaps even more impressive, William Lawrence was only 25 years old at the time of the award, the youngest Nobel Laureate ever. Certainly a role model for college students today!

Written by Daniel Rabinovich <drabinov@uncc.edu>. 